\title{
CANON NOVOHISPANO: LA BÚSQUEDA DE CRITERIOS DE EDICIÓN
}

\author{
Carmen Fernández Galán Montemayor \\ Universidad Autónoma de Zacatecas \\ carmenfgalan@gmail.com
}

\begin{abstract}
RESUMEN: En la pretendida conformación de un canon de literatura mexicana, y sin dejar las consideraciones básicas ya tradicionales en tales tópicos, no se puede soslayar la incorporación de los textos pergeñados en el llamado periodo novohispano. Lo escrito durante esos años supone, sin embargo, especiales retos. Desde la identificación más práctica sobre sus especificidades, en tanto la perspectiva de los géneros literarios, hasta las maneras en que la investigación especializada deberá utilizar para ponerlas nuevamente en circulación. Trazar un mapa que ilustre el camino, en términos editoriales, que nuestras letras novohispanas habrán de recorrer, es la intención fundamental del presente texto, al tiempo que subraya la vigencia de esta tradición literaria.
\end{abstract}

PALABRAS CLAVE: canon, literatura, edición, paratextos, tradición.

\section{CANON OF VICERROYALTY OF NEW SPAIN: IN SEARCH FOR EDITORIAL STANDARDS}

\begin{abstract}
In the hopeful composition of the Mexican literary canon, and without forgetting the necessary considerations that are now commonplace when regarding these topics, one cannot set to one side the incorporation of the texts from the period we commonly call novohispano. Nonetheless, what was written during that period possesses its own special challenges: from the identifying its own specific qualities from the perspective of the different literary genres, to the ways in which specialist research should approach this literature in order to bring it back to the forefront. To create a map that would illuminate the way, in editorial terms, which novohispano literature travels is the primary purpose of this essay while at the same time emphasizing the validity of this literary tradition.

KEYWORDS: canon, literature, edition, paratexts, tradition.
\end{abstract}

Recibido: 15/04/2015. Aceptado: 09/11/2016 
En nuestros días el concepto de canon ha sido revisitado y discutido. En especial a propósito de Harold Bloom (1994) y del ensayo póstumo de Italo Calvino "Por qué leer a los clásicos". En tal contexto de reescritura del canon de Occidente, las literaturas americanas ocuparán un nuevo lugar, pues al moverse el eje del mismo, todos sus componentes se dispersan. En el caso de México, Alberto Vital (2008) propone la revaloración de la obra poética de uno de los pilares de la literatura mexicana, Alfonso Reyes, y nos recuerda que las preferencias de lectura de los escritores no coinciden con las del lector común, y menos aún con la de los usuarios de la web, de modo que determinar el valor literario de una obra se ha tornado un asunto complicado, pues los modos de circulación de textos tienen distintas recepciones a través del tiempo.

Tendríamos que replantear la pregunta de Bloom sobre los textos fundamentales a leer: ¿qué debe leer un mexicano?, y agregar las siguientes: ¿cuáles textos conforman la lengua e identidad de la Nación mexicana?, ¿de qué tradición provienen y cómo la transforman?, ¿qué repertorios simbólicos construyen y cuál es su vigencia? Las ocasiones en que he preguntado a mis alumnos de licenciatura sobre los autores fundamentales de la literatura mexicana, siempre aparecen los nombres de Juan Rulfo y Octavio Paz (a veces Carlos Fuentes), junto con el del Sor Juana Inés de la Cruz, a quien conocen más como personaje que por su obra. ${ }^{1}$ Lo sobresaliente es que tres siglos de letras coloniales se sintetizan en una mujer mitificada más que leída, de manera que la memoria histórica queda oscurecida, igual que el verdadero conocimiento de su obra.

La conformación del canon mexicano, requiere una imagen clara de lo novohispano. Así como Eguiara y Eguren, o Beristáin y Souza² describieron la república de las letras en almanaques de autor para sus contemporáneos, se requiere una revisión crítica de obras y autores en el nuevo horizonte de recepción que posibilite la inclusión de escritores olvidados y de textos desvalorizados, pues así como los textos merecen ser recordados, hay otros que deben ser releídos. Bloom realizó un catálogo de autores bajo una línea de influencia para la literatura en lengua inglesa, considerando a Shakespeare como el eje del canon laico porque "define por igual a predecesores y legatarios" (Bloom, 1995: 34), mientras que Italo Calvino en ¿Por qué leer los clásicos? unió la idea de lo clásico (amén de

1. Hay numerosas polémicas de la crítica en torno a su vida y obra, y muchas novelas que la toman como protagonista, al grado de que ya hay una serie de televisión sobre ella.

2. La Bibliotheca Mexicana de Juan José Eguiara y Eguren en el siglo XVIII, continuada por su alumno José Mariano Beristáin y Souza como Biblioteca Hispanoamericana Septentrional en 1790, son catálogos bibliográficos de autores americanos. 
todas sus definiciones) y lo universal al texto plural de Roland Barthes (1971), es decir, un texto que nunca termina de decir lo que tiene que decir. Uno delimitó y creó una lista de autores, y otro expandió la idea de literatura hasta diseminarla.

De manera sintética el canon es el conjunto de obras que deben ser leídas, y a partir de eso, la prensa escrita en lengua castellana ha realizado diversas encuestas de los textos hispanoamericanos clave, lo que posteriormente se ha convertido en proyectos editoriales de un conjunto de clásicos para la enseñanza media o básica. La recuperación del pasado literario de México, requiere la inclusión y contextualización de obras que son parte fundamental del imaginario nacional y que son desconocidas. La idea de canon que se tomará como punto de partida será la de conjunto de textos a leer, que en el caso de la literatura novohispana, son los textos que hay que hacer libros, y desde ahí poder revisar los criterios de construcción de un canon novohispano.

\section{Estudios novohispanos}

La revaloración de la literatura colonial en México comienza alrededor de los años ochenta del siglo XX. En esa década hay un verdadero boom de los estudios coloniales con la aparición de grupos de investigadores preocupados por la recuperación de fuentes tanto científicas como literarias: el Seminario de Cultura Mexicana fundando en 1942 y el Centro de Estudios Literarios de la UNAM en 1956. Ambas instancias aportaron un enfoque sociológico y cultural sobre la literatura virreinal. De acuerdo a Pascual Buxó en "esa etapa se conjuntaron la moderna investigación científica documental con la revaloración estética del barroco” (Pascual Buxó 1994: 27). En 1982 se publica el ensayo de Octavio Paz sobre Sor Juana Inés de la Cruz, quien se vuelve autora clave de la cultura literaria e influencia del propio nobel de literatura mexicano. En 1985 el Colegio de México propone la edición crítica de obras en la Biblioteca novohispana; Luis Astey describe los procedimientos de edición en un manual para fijar los criterios de homogeneización de la colección, no así los parámetros de selección de obras. En 1987 aparece en Xalapa otro proyecto de ediciones críticas, enfocada a textos decimonónicos. En 1989 se publica Esplendores y miserias de los criollos, que como estudio crítico y antología resultó de gran divulgación, por lo que debe revisarse su papel en la elaboración del corpus novohispano, al que caracteriza como "letras barrocas":

Las letras barrocas se diferencian tanto de las renacentistas como de las ilustradas o modernas; no aspiran a la transparencia de los significados ni a la llaneza o preci- 
sión del lenguaje; no buscan fines didácticos ni la discusión crítica; no investigan ni conversan: son laberintos del conocimiento y fiestas de la expresión. Las palabras barrocas sueñan que son joyas, cifras herméticas, claves de prodigios algebraicos. (Blanco 1989, 2009: 20)

Otro hito fundamental para la investigación fue la publicación en 1994 del Catálogo de textos marginados novohispanos (Siglo XVIII y XIX) junto a otros proyectos de modernización de los acervos de la ciudad de México ${ }^{3}$. Con ello se recupera todo un territorio ignoto de las letras novohispanas marcado en su momento por la censura y donde coexisten tradiciones populares y cultas, así como una gran variedad de géneros literarios y/o textos de carácter científico.

La tarea de rescate y edición de textos coloniales ha sido continua junto con la revisión crítica de la historia literaria nacional. Cabe resaltar la permanencia del Encuentro Nacional de Investigadores del Pensamiento Novohispano, desde el año de 1987, así como el proyecto de una Historia de la literatura mexicana iniciada en 1986 y publicada en tres volúmenes entre los años de 1996 y 2011, por la editorial siglo XXI, y que constituye una revisión puntual de la literatura los siglos XVI al XVII y donde se observa el viraje de la filología hacia la historia cultura o del libro, igual que en la Historia de la cultura literaria en Hispanoamérica (20002010) traducida del italiano al español, que es una visión del mundo colonial que integra los virreinatos de México y Perú en lo que denominan "comunidad literaria hispanoamericana”. Cada vez son más los intentos de integración de las literaturas coloniales dentro de los proyectos revisionistas de la historia de las literaturas hispanoamericanas ${ }^{4}$, aunque se ha prestado poca atención al canon escolar, es decir, a los textos que deben ser leídos y que sean de actualidad.

La cuestión novohispana (más allá de los debates sobre neocolonialismo) resulta un punto central de la discusión en torno al concepto de literatura hispanoamericana tanto como en el concepto de literatura en sí mismo, y de ahí que las recientes historias de la literatura hagan énfasis en aspectos sociales como: educación en colegios y seminarios, imprenta y monopolios, rol de la Inquisición

3. Los trabajos precursores sobre Inquisición en México son los de Monelisa Pérez-Marchand (1945). Dos etapas ideológicas del S. XVIII en México a través de los papeles de la Inquisición. México: Colegio de México y de Solange Alberro (1988). Inquisición y sociedad en México 1571-1700. México: FCE.

4. Sobre la revisión de la historiografía literaria véase: Beatriz Garza Cuarón y Georges Baudot (1996). Historia de la literatura mexicana 1. México: Siglo XXI-UNAM y Carmen Eliza Acosta Peñalosa, "Lectura crítica de las historias de la literatura latinoamericana” en Pascual Buxó, J. (coord.) (2011). Construcción y crítica del corpus literario hispanoamericano. Estudios de aproximación. México: Instituto de Investigaciones Bibliográficas UNAM. 
y de la monarquía borbónica en la configuración del sistema literario. El asunto de los tipos de discurso ha resultado de difícil caracterización porque las fronteras entre géneros y tradiciones populares son difusas, además de que en el marco de la fiesta barroca las artes funcionaban en sincretismo y simultaneidad: teatro, pintura, arquitectura y poesía se funden en rituales de lealtad, que a la mirada crítica actual resultan difíciles de comprender.

Otro problema de las historias de la literatura colonial es que reproducen en su mayoría los esquemas de la historias anteriores, si bien han tratado de superar sus prejuicios, todavía se siguen centrando en las "figuras estelares”, resultado de un criterio selectivo y de la falta de un corpus de obras que fueron desacreditas o desatendidas por los primeros antologadores. Dalmacio Rodríguez realiza una revisión historiográfica tratando de superar el prejuicio de lo canónico:

Se puede decir que el principio de selectividad, en tanto que se opone al de totalidad, no favoreció la constitución de un corpus de la literatura novohispana. Tampoco ayudó el contraste tan marcado entre los autores consagrados y la muchedumbre de escritores que en su mayoría no mereció siquiera la categoría de autores secundarios, sino de simples poetrastos o versificadores [...] El criterio canónico marcado con tan fuerte contraste implicó la exclusión, distorsión y denuesto de los autores, obras y géneros que estaban al margen del canon. (Rodríguez 2011: 59)

Si el canon ha resultado en demérito de la literatura colonial, debemos rescribirlo y para ello se requiere la constitución de un corpus de obra y autores que quedaron en la sombra tanto por circunstancias de su época, como por la historiografía literaria posterior. Aunque hay notables logros en lo que corresponde a diccionarios de escritores, todavía hay catálogos de autores y obras pendientes (sin contar el vasto corpus mesoamericano), especialmente de literatura neolatina. Considero que para completar esa tarea se requieren ediciones modernas de textos novohispanos, ya sean críticas, anotadas, facsímiles o antologías, no obstante es necesaria una reflexión puntual sobre los criterios de edición de este tipo de obras atendiendo a sus características.

\section{Criterios de edición de textos novohispanos}

La historia literaria nacional requiere la inclusión de textos que en su momento circularon principalmente de dos formas: de manera manuscrita y clandestina, o de manera impresa bajo mecenazgo, lo que llevó a que muchas obras permanecieron 
bajo el olvido, ya fuera por la censura o porque se imprimieron sólo una vez. La recuperación del patrimonio literario del México colonial exige además la revisión del concepto de lo literario bajo géneros discursivos que hoy no son considerados literatura.

La edición crítica de textos antiguos, como labor filológica, implica el conocimiento del horizonte de recepción en que se produjo y circuló una obra, y que abarca el universo de saberes en que se inscriben las prácticas de escritura. Similar al trabajo del traductor, el editor debe tomar decisiones para la modernización del texto así como para respetar las fuentes de la historia de la lengua y del libro. La inteligibilidad y aceptación de formas literarias lejanas en el tiempo requieren de un ejercicio hermenéutico y de traducción (a veces entre lenguas, a veces entre códigos) para la correcta transmisión de un texto original, ya sea único testimonio o resultado de la recomposición entre varias versiones.

En el afán y en la tarea de recuperación participan varias disciplinas, principalmente historiadores y literatos, no obstante a veces se confunde el valor documental o testimonial de una obra con su valor literario. Hay una gran diversidad de estilos de ediciones anotadas, ya que el material es tan heterogéneo que se dificulta establecer un criterio único de edición para hacer accesibles los textos a los lectores contemporáneos. Todo intento por homogeneizar los criterios de edición conduce al debate entre hacer colecciones y unificar todos los criterios o respetar la diferencia de cada texto, es decir, si lo esencial es hacer accesible al lector contemporáneo la obra ¿cómo preservarla a la vez en tanto testimonio de la lengua? La pregunta es ¿modernizar o hacer versiones diplomáticas?5

La mayoría de los intentos de rescate establecen la norma de modernizar sin atender al género o tipo textual y sus condiciones de transmisión, cuando generalmente se aconseja hacer versiones diplomáticas cuando se trata de un solo testimonio u obras autógrafas. Dependiendo de los criterios de fijación del texto, los estudios críticos se distribuyen en notas críticas y de erudición que por lo común se consignan juntas a pie de página, aunque a veces, cuando las aclaraciones semánticas son muy extensas, se presentan en glosario aparte. Los aparatos críticos se dividen en a) notas críticas: destinadas a las condiciones materiales del texto, legibilidad y lagunas, enmiendas y tachaduras, cotejo de versiones y variantes, y b) notas de erudición: aclaraciones semánticas y contexto histórico.

5. Actualmente existen tres proyectos de rescate y edición de textos novohispanos donde participan grupos de investigación de las Universidades de Zacatecas, liderado por Isabel Terán, San Luis Potosí, coordinado por Ramón Manuel Pérez Martínez, y el del Seminario de Cultura Mexicana a cargo de José Pascual Buxó, donde se discuten estos criterios. 
Respecto a la extensión de los textos a rescatar, se han hecho pocas ediciones de obras completas, por lo común el corpus novohispano se edita ya sea en fragmentos seleccionados por un antologador, o en libros donde una sola obra recibe todo el protagonismo. Pareciera que los criterios académicos se imponen en perjuicio del lector común, y de la conformación de un conjunto de obras de lectura obligada.

Hay sus notables excepciones, como la antología de Poesía novohispana de Martha Lilia Tenorio, que en primer lugar se reconoce como riesgo ya que "ninguna selección puede ser definitiva, completa gustosa para todos, ni del todo justa” (2010: 81), y que se propone ser complementaria de la que realizara Alfonso Méndez Plancarte en la década de los cuarenta, y donde la selección de autores se realizó con base en tradición poética y no en lugar de origen. Esta obra, junto con las ediciones de poesía culta y marginal de Margarita Peña, y la numerosas antologías de literatura novohispana donde circulan fragmentos de poesía culta, permiten demostrar la presencia de un canon poético, en tanto conjunto de textos seleccionados y explicados en anotaciones léxicas e históricas y del que hay numerosos estudios.

Si el canon se define por influencia, la tradición poética novohispana se basa en las preceptivas barrocas de Baltazar Gracián, Juan de Caramuel y Juan Díaz Rengifo (por mencionar a los más importantes), y en este último se fusionan modelos italianos y españoles, que trazan una línea que lleva desde la poesía petrarquista hasta el gongorismo que fue el modelo de creación en las colonias, base de un imperio y sus aparatos simbólicos.

Cabe detenerse un momento en los aspectos lingüísticos de la edición de textos antiguos. Gran parte de la producción literaria novohispana está escrita en latín, cuya caracterización está pendiente: "No existe una gramática o un diccionario de neolatín. Se han escrito léxicos regionales de documentos, esbozos de gramáticas, también regionales” (Heredia 2001: 227). Al igual que las filologías clásicas, el estudio del neolatín requiere conocimientos de paleografía, lengua, historia, crítica textual, la misma filología clásica, y a veces hasta saberes de hermetismo.

En el caso de textos bilingües latín y castellano, la traducción de latín torna compleja debido a cuestiones de transmisión de textos, ya que las citas de fuentes clásicas o bíblicas eran la mayoría de las veces tomadas de polianteas o compilaciones donde circulaban como frases fuera de su contexto original. Un mayor problema de transmisión lo constituyen las citas de memoria u oídas; muchos editores 
toman la decisión de corregir la cita con base en la fuente "original”, en vez de consignar las variantes lingüísticas para la caracterización del proceso de latinización (o castellanización) y dejar en nota a pie de página la corrección explicada.

Los modelos de edición más frecuentes son la modernización y el facsímil, las versiones diplomáticas son realizadas sólo por lingüistas ${ }^{6}$ y por contados estudiosos de la literatura. Cuando se trata de traducciones, la práctica común en México han sido ediciones eclécticas que toman como base traducciones modernas de textos clásicos, de acuerdo a Belem Clark los tipos de edición dentro de la tradición de la filología mexicana son:

Edición crítica de obras y materiales hemerográficos; 2) ediciones anotadas de inéditos, epistolarios o memorias; 3) ediciones de índices y/o facsimilares de revistas literarias; 4) edición de estudios fonográficos o biográficos; 5) edición de antologías, hemerografías y de diccionarios (Clark 2001: 99).

En lo que corresponde a los estudios novohispanos la norma ha sido la realización de ediciones críticas y antologías que todavía se conservan como libro impreso, aunque cada vez son más las ediciones digitales, como los libros de emblemas que circulan en la web7 ${ }^{7}$ Portadas, índices, prólogos, dedicatorias, glosas al margen, grabados, y tipos de imprenta, se convierten en mapas de bits en las pantallas líquidas donde los textos cobran un distinto sentido. Los paratextos condicionan la recepción de los libros y hace falta reflexionar sobre el traspaso del texto antiguo a los modos de producción de libro (impreso o digital) que transforman sus modos de circulación.

En el paso del manuscrito al libro moderno puede rescribirse la historia literaria. En el contexto novohispano los impresores funcionaban como marca de autor y tenían monopolios sobre lo que debía pasar a la imprenta, eran necesarias muchas licencias para publicar, y en cierta forma la censura inquisitorial marcó el destino de la literatura al constituir su propia marginalidad. El estilo oscila por tanto entre la modesta barroca y múltiples códigos de lealtad, y entre una literatura perseguida anónima y satírica. Hoy esos libros circulan en un escenario de derechos de autor y mecenazgos de estado.

6. Véanse las transcripciones del Grupo de estudio del español colonial mexicano del Instituto de Investigaciones Filológicas de la UNAM en URL: http://www.iifl.unam.mx/coreecom/ (marzo 2015).

7. Véase al respecto: Carmen Fernández Galán, "Los umbrales del libro: estudios de emblemática”, en Noé Héctor Esquivel Estrada (comp.) (2013), Pensamiento novohispano, número 14, Universidad Autónoma del Estado de México. 
La primera imprenta de América surge Nueva España en 1539. La materia prima, el papel, era importado y transportado desde España que retuvo el monopolio de su fabricación, desde el puerto de Veracruz se distribuía a la ciudad de México. Para 1700, la Nueva España contaba ya con imprentas en cinco de sus principales ciudades: México, Puebla, Guadalajara Veracruz y Oaxaca [...] Estas empresas, generalmente familiares, publicaban sólo los libros que contaban con las licencias y privilegios correspondientes, y, por supuesto, sólo aquellas cuyos autores o sus mecenas aportaban los recursos para su impresión, de modo que las imprentas, indirectamente, eran un filtro ideológico y literario de las obras impresas que circularon en Nueva España. (Terán y Fernández Galán 2013: 140)

Los tipos de obras que se imprimían, aparte de cartillas, catecismos y catones, eran obras de circunstanciales destinadas a festejos, e híbridas, dando origen a nuevos géneros literarios como el sermón y los libros de exequias. Unos cuantos certámenes literarios tuvieron la fortuna de ser impresos, pero queda todavía un gran corpus de literatura manuscrita pendiente por explorar. Durante la transición ideológica del siglo XVIII aparecerán publicaciones periódicas de carácter científico como la Gaceta Literaria y el Mercurio Volante, que combinan diferentes géneros discursivos y donde comienza a debatirse la idea de literatura.

Algunos problemas de edición están estrechamente ligados al género discursivo. Para los textos poéticos una modernización puede sacrificar acrósticos, retrógradas, además de ritmo y sonoridad; igual ocurre con los textos satíricos donde es riesgoso alterar anagramas y nombres en clave. Mención especial merecen las relaciones de festejos y las écfrasis de túmulos funerarios, pues son obras incluidas dentro de esferas rituales y donde muchas artes entran en juego, algunas de ellas contienen grabados o imágenes que una edición crítica debe restituir.

En los últimos años se ha ido conformando un canon de ficción virreynal, resultado del cambio de concepto de literatura que retoma los géneros de la crónica y relaciones de viaje junto con literatura religiosa que saltan del terreno del mito y las creencias al estatuto de ficción en un horizonte de recepción posterior y laico. He aquí una lista de obras que se consideran ficción:

Los sirgueros de la Virgen de Francisco Bramón, El pastor de nochebuena de Juan de Palafox y Mendoza, El Carnero de Juan Rodríguez Freyle, El cautiverio feliz de Francisco Núñez de Pineda y Bascullán, La autobiografía de la monja Alférez atribuida a Catalina de Erauso, Infortunios de Alonso Ramírez de Carlos de Sigüenza y Góngora, y La endiablada de Juan de Morovejo y de la Cerda, así como algunos cuentos intercalados, muy pocos por cierto, en alguna crónica.

(Pranzetti 2010: 390) 
En el libro Trinidad Barrera Por lagunas y acequias. La hibridez de la ficción novohispana (2013) se reúnen un conjunto de ensayos que completan esta lista con otras obras, que son: La heroína mexicana (anónima) ${ }^{8}$, El siglo de Oro en las selvas de Erífile de Bernardo de Balbuena, Sueño de sueños de José Mariano Acosta, La Portentosa vida de la muerte de Joaquín Bolaños9 , y Soñados regocijos de la Puebla, una obra de teatro considerada moderna.

En lo que respecta a la crónica, Walter Mignolo (1982), ha tomado pasajes que se leen como relatos maravillosos y/o fantásticos; otro trabajo que se suma a la lectura fantástica de la crónica es la tesis doctoral de Marina Ruano (2014), donde ha recopilado fragmentos relaciones y crónicas y cuyo análisis comparativo permite encontrar estrategias retóricas en la formulación de un género independiente. Otra obra paralela es Literatura de viajes. El viejo y el nuevo Mundo (1999), en tanto constituye de otro corpus "ficcional", en una excursión por la literatura que agrupa textos bajo una línea genérica y temática.

El carácter ficcional de estas obras puede ser todavía cuestionable, como lo ha demostrado Antonio Lorente Medina en los Infortunios de Alonso Ramírez, que está lejos de ser una ficción, pues se trata de un relato testimonio recogido por el autor, sin embargo, en términos de fortuna y transmisión ha sido más conveniente que se lea como mentira. La sátira es otro género que merece especial mención, ya que en su intención de enmascaramiento recurre a la ficción ${ }^{10}$. Nancy Vogeley propone que el origen de la novela novohispana está vinculado a la sátira, a propósito de Lizardi, o de la literatura panegírica, a propósito de Bolaños (2011: 223-230).

Limítrofe entre realidad y fantasía está el teatro, ya sea evangelizador o cortesano. Dos autores se ha robado el protagonismo en las ediciones sobre teatro: Sor Juana Inés de la Cruz (nuevamente) y Juan Ruiz de Alarcón. Existen otras compilaciones de teatro como obra completa que integran otros poetas neolatinos, como la edición de la obra dramática de Cayetano Cabrera y Quintero realizada por Claudia Parodi (1976). Apenas comienzan a integrarse en el canon de teatro los autos triunfales de Francisco Bramón, las comedias y autos de Luis Sandoval

8. Francisco de Paula Urvizu (ed.) (2008). La heroína mexicana, rescate, transcripción y estudio de Isabel Terán. México: Terracota.

9. De la que hay una edición crítica realizada por el Colegio de México en 1992 y una versión facsimilar del año 1983 coedición del INBA y Premia. Para un estudio especializado de esta obra véase: Isabel Terán (1997). Los recursos de la persuasión: La portentosa vida de la muerte de fray Joaquín Bolaños. México: El Colegio de Michoacán-UAZ.

10. Véase: Szicigias y quadraturas lunares de Manuel Antonio de Rivas (2010), Edición crítica de Carmen F. Galán. México: Factoría-UAZ. 
y Zapata, de Matías de Bocanegra, de Alonso Ramírez de Vargas, de Francisco Acevedo, (Poot 2002) quienes poco a poco van completando una imagen de la producción teatral. El estudio de Miguel Sabido (2014) sobre los coloquios de México, recupera las pastorelas, el día de muertos, las fiestas de Guadalupe, la adoración de los Reyes entre otras manifestaciones del teatro popular que todavía se realizan en el país.

Estas notas son una tentativa de trazar un mapa que ilustre el camino que en términos editoriales va recorriendo la literatura novohispana, dando lugar a un conjunto de obras cuya circulación contemporánea merece revisión constante, puesto que el afán de rescate se ha llevado al extremo de incorporar todas las obras de las que haya testimonio sin demostrar su vigencia. Considerando que las fronteras geopolíticas y las culturales son distintas, la selección no debe limitarse a periodo colonial mexicano, delimitado por la Conquista y la Independencia, ya que hay líneas de continuidad de esa tradición literaria que llegan hasta siglo XXI.

Lo importante es que ya sea en obras completas, antologías, fragmentos, tomos, entregas, pasquines, o expedientes inquisitoriales, la literatura novohispana sigue vigente.

\section{Bibliografía}

BARRERA, T. (ed.) (2013). Por lagunas y acequias. La hibridez de la ficción novohispana. Berna: Peter Lang.

BARTHES, R. (1971, 1987). "De la obra al texto” en El susurro del lenguaje. Más allá de la palabra y la escritura. Barcelona: Paidós.

BLANCO, J. J. (1989: 2009). Esplendores y miserias de los criollos. La literatura en la Nueva España. México: Cal y arena.

BLECUA, A. (1983, 1990). Manual de crítica textual. Madrid: Castalia.

BLOOM, H. (1994, 1995). El canon occidental, trad. de Damián Alou. Barcelona: Anagrama.

CANO AGUILAR, R. (2000). Introducción al análisis filológico. Madrid: Castalia.

CLARK DE LARA, B. y CURIEL DEFOSSÉ, F. (coords.) (2001). Filología mexicana. México: UNAM.

CLARK DE LARA, B. et al. (eds.) (2009). Crítica textual. Un enfoque multidisciplinario para la edición de textos. México: El Colegio de México-UNAM-UAM.

HEREDIA CORREA, R. (2001). "Pequeñas confesiones de un aprendiz de traductor” en Clark de Lara, B. y Curiel Defossé, F. (coords.), Filología mexicana. México: UNAM. 
MIGNOLO, W. (1982). “Cartas, crónicas y relaciones del descubrimiento y conquista” en Iñigo Madrigal, L. (coord.), Historia de la literatura hispanoamericana I. Época colonial. Madrid: Cátedra.

PARODI, C. (1976). Cayetano Javier de Cabrera y Quintero. Obra dramática. Teatro novohispano del siglo XVIII. México: UNAM.

PASCUAL BUXÓ, J. y HERRERA, A. (eds.) (1994). La literatura novohispana. Revisión crítica y propuestas metodológicas. México: UNAM.

PÉREZ PRIEGO, M. A. (1997). La edición de textos. Madrid: Síntesis.

POOT HERRERA, S. (2002). "Cien años de teatralidad” en Chang Rodríguez, R. (coord.), Historia de la literatura mexicana 2. La cultura letrada en la Nueva España del siglo XVII. México: Siglo XXI-UNAM.

PUCCINI, D. y YURKIEVICH, S. (2000-2010). Historia de la cultura literaria en Hispanoamérica, Rodríguez Aguilar J. C. et al. (trads.). México: FCE.

RODRÍGUEZ HERNÁNDEZ, D. (2011). “Tradición historiográfica y corpus de la literatura novohispana” en Pascual Buxó, J. (coord.), Construcción y crítica del corpus literario hispanoamericano. Estudios de aproximación. México: Instituto de Investigaciones Bibliográficas UNAM.

RUANO, M. (2014). La ficcionalización de los discursos del descubrimiento y de la conquista de Hispanoamérica. Tesis de Doctorado en Humanidades y Artes, México: Universidad Autónoma de Zacatecas.

SABIDO, M. (2014). Teatro sagrado. Los “coloquios” de México. México: Siglo XXI.

TERÁN, I. y FERNÁNDEZ GALÁN, C. (2013). “Autoría, censura y poder: siglo XVIII y albores del XIX”, en Pérez Martínez, R. M. y González Varela, S. A. (eds.), Poder y alteridad. Perspectivas desde la antropología, la literatura y la historia. Vigo: Editorial Academia del Hispanismo.

VITAL, A. (2008). El canon intangible. México: Terracota, La escritura invisible. VOGELEY, N. y RAMOS MEDINA M. (2011). Historia de la literatura mexicana 3. Cambios de reglas, mentalidades y recursos retóricos en la Nueva España del siglo XVIII. México: Siglo XXI-UNAM. 